\title{
Antioxidant activities and simultaneous HPLC-DAD profiling of polyphenolic compounds from Moringa oleifera Lam. Leaves grown in Bangladesh
}

\author{
Ahmed, K.S., Jahan, I.A., Jahan, F. and *Hossain, H. \\ Chemical Research Division, BCSIR Laboratories, Dhaka, Bangladesh Council of Scientific and Industrial \\ Research (BCSIR), Dhaka-1205, Bangladesh.
}

\begin{abstract}
Article history:
Received: 30 July 2020

Received in revised form: 27 August 2020

Accepted: 14 October 2020

Available Online: 7 February 2021
\end{abstract}

\section{Keywords:}

Moring a oleifera leaves, HPLC-DAD,

Antioxidant activity,

Polyphenolic compounds

DOI:

https://doi.org/10.26656/fr.2017.5(1).410

\begin{abstract}
Moringa oleifera Lam. has been used as a traditional medicine for the treatment of several diseases. In this study, the antioxidant activity and simultaneous HPLC profiling of polyphenolic compounds in $80 \%$ ethanol and water extracts of $M$. oleifera tender and mature leaves available in Bangladesh were investigated. The $80 \%$ ethanol extract of $M$. oleifera tender leaves contained high concentration and more amount of 3,4dihydroxybenzoic acid, (-) epicatechin and rosmarinic acid $(201.32 \pm 1.94,213.08 \pm 1.96$ and $133.84 \pm 1.42 \mathrm{mg} / 100 \mathrm{~g}$ of dry extract, respectively) than that of mature leaves $(82.55 \pm 1.09,141.86 \pm 1.10$ and $16.23 \pm 0.76 \mathrm{mg} / 100 \mathrm{~g}$ of dry extract, respectively). On the other hand, the water extract of M. oleifera tender leaves contained a high concentration of catechin hydrate, trans-ferulic acid and quercetin (530.05 $\pm 1.91,166.38 \pm 0.90$ and $771.74 \pm 1.34 \mathrm{mg} / 100 \mathrm{~g}$ of dry extract, respectively) than that of mature leaves (207.21 $\pm 0.90,62.42 \pm 0.45$ and $483.25 \pm 1.04 \mathrm{mg} / 100 \mathrm{~g}$ of dry extract, respectively). It was also found that 3,4-dihydroxybenzoic acid, catechol, p-coumaric acid and trans-cinnamic acid were detected only in $80 \%$ ethanol extract of $M$. oleifera leaves but syringic acid was identified in the water extract. In DPPH free radical scavenging activity test, $\mathrm{IC}_{50}$ values of $80 \%$ ethanol extract of tender leaves (EETL), $80 \%$ ethanol extract of mature leaves (EEML), water extract of tender leaves (WETL) and water extract of mature leaves (WEML) were found to be moderately significant $(105.50 \pm 1.05,115.00 \pm 1.14$, $216.00 \pm 1.34$ and $269.50 \pm 1.56 \mu \mathrm{g} / \mathrm{mL}$, respectively) when compared to the $\mathrm{IC}_{50}$ value of ascorbic acid, $3.32 \pm 0.07 \mu \mathrm{g} / \mathrm{mL}$. The polyphenolic compounds are responsible for antioxidant activity. On the basis of the present study, it can be suggested that the leaves show antioxidant activity and it's contained a significant amount and different types of polyphenolic compounds. Standardized polyphenolic compounds from M. oleifera leaves could be used as a better source of natural antioxidant supplement.
\end{abstract}

\section{Introduction}

Moringa oleifera Lam, is a tree of a monogeneric family, native to the sub-Himalayan tracts of Bangladesh, India, Pakistan, and Afghanistan. It's being also grown in different countries of the world like as West, East and South Africa, Tropical Asia, Latin America, The Caribbean, Florida and The Pacific Islands (Fahey, 2005). It is considered one of the world's most useful trees because almost every part of the tree has some nutritional, medicinal and other beneficial properties (Luqman et al., 2012). Different parts of the $M$. oleifera tree are containing high amounts of Vitamin $\mathrm{C}$ and Mineral (Ahmed et al., 2016; Ahmed et al., 2018). On the other hand, $M$. oleifera seed kernels show good antioxidant activity (Jahan et al., 2018). The $M$. oleifera plant is used in several purposes such as for human consumption, medicinal, animal fodder, water purification, fertilizer, living fence, alley cropping, natural pesticide, fuelwood and growth hormone for the plant (Bashir et al., 2016; Falowo et al., 2018). The medicinal properties have been attributed to phytochemical compositions of the various parts of Moringa such as roots, bark, leaf, flowers, fruits, and seeds (Anwar et al., 2007; Kumar et al., 2010). Moringa tree was also used in the folk medicine where the infusions, decoctions and concoctions of various parts of this plant are used in the treatment of several ailments such as cardiac and circulatory stimulants; possesses antitumor, antipyretic, antiepileptic, anti-inflammatory, 
antiulcer, antispasmodic, diuretic, antihypertensive, cholesterol lowering, antioxidant, antidiabetic, hepatoprotective, antibacterial, and antifungal activities (Anwar et al., 2007).

Oxidative stress is a physiological condition resulting from an imbalance between reactive oxygen species (ROS) and antioxidants in favor of the former. Oxidative stress is the underlying condition responsible for several chronic diseases such as diabetes, hypertension, inflammation, and cancer (Nimse and Pal, 2015). Management of oxidative stress involves the use of antioxidants, which are molecules intended to quench or trap ROS and prevent oxidative damage (Sreelatha and Padma, 2009; Nimse and Pal, 2015). With increasing desire to adopt healthy lifestyles, consumers are declining more and more from the use of synthetic antioxidants due to their side effects (Win et al., 2011) in favor of dietary sources of antioxidants (Ibrahim et al., 2013). This trend is further justified by the fact that antioxidant components from dietary sources are relatively safe. The extracts of $M$. oleifera leaves have exposed potent antioxidant activity against free radicals, prevent oxidative damage to major biomolecules and afford significant protection against oxidative damage (Amaglo et al., 2010). Several phenolic compounds and alkaloids are reported to be responsible for the beneficial health effects (Stohs and Hartman, 2015; Cuellar-Nuñez et al., 2018). Polyphenols are secondary compounds broadly dispersed in the plant kingdom. They are divided into several classes' phenolic acids, flavonoids, stilbenes, and lignans, which are distributed in plants and food of plant origin (Manach et al., 2004; Manach et al., 2005). There is proof that phenolic substances exhibit antioxidant properties by stopping the oxidation of LDL lipoprotein, platelet aggregation, and damage of red blood cells (Cheynier, 2005). Moreover, phenolics act as metal chelators; antimutagens and anticarcinogens; antimicrobial agents; clarifying agents (Proestos et al., 2005).

This study was designed to evaluate the antioxidant activity and qualitative and quantitative analysis of polyphenolic compounds in $80 \%$ ethanol and water extracts of tender and mature leaves of $M$. oleifera.

\section{Materials and methods}

\subsection{Plant material}

A group of leaves samples separated into tender leaves and mature leaves were collected from M. oleifera tree growing at Dhaka, Bangladesh. The collected leaves were segregate on the bases of leaves color. Tender leaves were light green (aged between 1 and 1.5 months old), and mature leaves were dark green (aged between 3 and 3.5 months old) which reported by Shuib et al. (2011). After that, all leaves were washed separately in water and then dried in a freeze dryer (Alpha 2-4 LD plus, Christ, Germany) at $-56^{\circ} \mathrm{C}$ for $32 \mathrm{hrs}$ to constant weight for moisture determination. Finally, the sample was pulverized in a mill to get $M$. oleifera tender and mature leaves fine powder.

\subsection{Preparation of $80 \%$ ethanol and water extracts}

One gram each of the powdered samples was weighed and extracted in $100 \mathrm{~mL} 80 \%$ ethanol and distilled water for $24 \mathrm{hrs}$ on an orbital shaker. The extract was further filtered using Whatman filter paper No. 1. Thereafter, the filtrated sample of $80 \%$ ethanol was dried using a rotator evaporator and water extracted was dried by freeze dryer. After that, $80 \%$ ethanol extract of tender leaves, $80 \%$ ethanol extract of mature leaves, water extract of tender leaves and water extract of mature leaves were labeled by EETL, EEML, WETL and WEML. Finally, both dried extracts obtained was kept at $4^{\circ} \mathrm{C}$ for subsequent analysis.

\subsection{Chemicals and Reagents}

DPPH (2,2-diphenyl-1-picrylhydrazyl), Gallic acid, 3,4-Dihydroxybenzoic acid, Catechin hydrate, Catechol, (-) Epicatechin, Caffeic acid, Vanillic acid, Syringic acid, Rutin hydrate, p-Coumaric acid, trans-Ferulic acid, Rosmarinic acid, Myricetin, Quercetin, trans-Cinnamic acid and Kaempferol were purchased from SigmaAldrich (St. Louis, MO, USA). Water (HPLC), Acetonitrile (HPLC), Methanol (HPLC) was collected from Active Fine Chemicals Ltd. (Bangladesh) and Acetic acid (HPLC) and Ethanol were obtained from Merck (Darmstadt, Germany).

\subsection{DPPH free radical scavenging activity test}

The antioxidant activity of $M$. oleifera tender and mature leaves were determined following one complimentary method such as DPPH free radical scavenging activity tests. The method of Govindarajan (Govindarajan et al., 2003) was used for performing the DPPH radical scavenging activity. Each sample extracts $(2 \mathrm{~mL})$ and $2 \mathrm{~mL}$ DPPH $(0.1 \mathrm{mM})$ solution were mixed. Vortex and allowed to stand at the dark place for 30 mins. The absorbance of the mixture was read against a blank at $517 \mathrm{~nm}$ using a double beam Analykjena UV/ Visible spectrophotometer (Model 205, Jena, Germany). The radical scavenging activity was expressed as the inhibition percentage (I \%) and calculated as per the equation:

$$
I(\%)=\left(A_{\text {blank }}-A_{\text {sample }} / A_{\text {blank }}\right) \times 100
$$

Where $A_{b l a n k}$ is the absorbance of the control 
(containing all the reagents except the testing compound), and $\mathrm{A}_{\text {sample }}$ is the absorbance of the experimental sample with all reagents. The $\mathrm{IC}_{50}$ value (the concentration of a sample required to scavenge $50 \%$ DPPH radical) was calculated from the plot of inhibition (\%) against the concentration of the extract. All determinations were carried out in triplicate and their average was noted. Ascorbic acid was used as the standard antioxidant.

\subsection{Preparation of working standard solutions for HPLC}

Sixteen (16) phenolic standards were dissolved with methanol in a $25 \mathrm{~mL}$ volumetric flask to produce stock standard solutions. The concentrations of stock solutions ranged from were 4.0 to $50 \mu \mathrm{g} / \mathrm{mL}$. The appropriate volumes of each stock solution were mixed together and then diluted serially to prepare the working standard solutions. All solutions were stored under refrigeration.

\subsection{HPLC analysis}

HPLC analysis was performed on a Shimadzu (LC20A, Japan) equipped with a binary solvent delivery pump (SIL-20A HT), an autosampler (SIL-20A HT), column oven (CTO-20A) and a photodiode array detector (SPD-M20A) and controlled by the LC solution software (Lab Solution Separation was performed using Luna $\mathrm{C}_{18}(5 \mu \mathrm{m})$ Phenomenex column $(4.6 \times 250 \mathrm{~mm})$ at $33^{\circ} \mathrm{C}$. The mobile phase composed of A $(1 \%$ acetic acid in acetonitrile) and $\mathrm{B}$ (1\% acetic acid in water) with gradient elution: $0.01-20$ mins, solution $\mathrm{A} 5-25 \%$ and solution B 95-75\%; 20-30 mins, solution A $25-40 \%$ and solution B 75-60\%; 30-35 mins, solution A 40-60\% and solution B $60-40 \% ; 35-40$ mins, solution A $60-30 \%$ and solution B 40-70\%; 40-45 mins, solution A $30-5 \%$ and solution B 70-95\%; and 45-50 mins, solution A 5\% and solution B 95\% was used in this study. The sample injection volume was $20 \mu \mathrm{L}$ and the flow-rate was set at $0.5 \mathrm{~mL} / \mathrm{min}$. The UV detector was set at $270 \mathrm{~nm}$ and applied for validation of method and analysis. The mobile phase was filtered through a $0.45 \mu \mathrm{m}$ Nylon 6,6 membrane filter (India) and degassed under vacuum. For the preparation of calibration curve, a standard stock solution was prepared in methanol containing gallic acid (20 $\mu \mathrm{g} / \mathrm{mL}) ; 3$,4-dihydroxybenzoic acid $(15 \mu \mathrm{g} / \mathrm{mL})$; catechin hydrate $(50 \mu \mathrm{g} / \mathrm{mL})$; catechol, (-) epicatechin, rosmarinic acid (30 $\mu \mathrm{g} / \mathrm{mL}$ each); caffeic acid, vanillic acid, syringic acid, rutin hydrate, $\mathrm{p}$-coumaric acid, transferulic acid, quercetin (10 $\mu \mathrm{g} / \mathrm{mL}$ each); myricetin, kaempferol $(8 \mu \mathrm{g} / \mathrm{mL}$ each); trans-cinnamic acid (4 $\mu \mathrm{g}$ / $\mathrm{mL})$.

\subsection{Statistical analysis}

The results of the three replicate experiments were pooled and expressed as mean \pm standard deviation (SD).

\section{Results and discussion}

\subsection{DPPH free radical scavenging activity}

DPPH free radical scavenging activity of the EETL, EEML, WETL and WEML were found to be increased with the increase of concentration of the extract (Table 1). The extract of EETL, EEML, WETL and WEML exhibited $84.24 \pm 0.24 \%, 75.61 \pm 0.48 \% 71.55 \pm 0.75 \%$ and $67.64 \pm 0.93 \%$ respectively, radical inhibitions at $400 \mu \mathrm{g} /$ $\mathrm{mL}$ whereas at the same concentration the standard ascorbic acid exhibited $97.15 \pm 0.03 \%$ inhibitions. IC $_{50}$ values of EETL, EEML, WETL and WEML were found to be significant $(105.50 \pm 1.05, \quad 115.00 \pm 1.14$, $216.00 \pm 1.34$ and $269.50 \pm 1.56 \mu \mathrm{g} / \mathrm{mL}$, respectively) when compared to the $\mathrm{IC}_{50}$ value of ascorbic acid, $3.32 \pm 0.07 \mu \mathrm{g} / \mathrm{mL}$. $\mathrm{IC}_{50}$ values of $80 \%$ ethanol extract are lower than water extract may be due to the presence of more number of polyphenolic compounds. On the other hand, may be due to the presence of a higher concentration of polyphenolic compounds, $\mathrm{IC}_{50}$ values of tender leaves is lower than mature leaves in both extracts. The antioxidants interact with DPPH, a purple colored stable free radical and convert to colorless 1,1-

Table 1. DPPH radical scavenging activity of $M$. oleifera leaves (tender and matured) and standard ascorbic acid

\begin{tabular}{cccccc}
\hline $\begin{array}{c}\text { Concentration of } \\
\text { sample }(\mu \mathrm{g} / \mathrm{mL})\end{array}$ & $\begin{array}{c}\text { \% inhibition } \\
\text { by EETL }\end{array}$ & $\begin{array}{c}\text { \% inhibition } \\
\text { by EEML }\end{array}$ & $\begin{array}{c}\text { \% inhibition } \\
\text { by WETL }\end{array}$ & $\begin{array}{c}\text { \% inhibition } \\
\text { by WEML }\end{array}$ & $\begin{array}{c}\text { \% inhibition by } \\
\text { Ascorbic acid }\end{array}$ \\
\hline 0 & $0.00 \pm 0.00$ & $0.00 \pm 0.00$ & $0.00 \pm 0.00$ & $0.00 \pm 0.00$ & $0.00 \pm 0.00$ \\
2.5 & $3.17 \pm 0.31$ & $2.83 \pm 0.14$ & $2.54 \pm 0.15$ & $2.38 \pm 0.19$ & $40.50 \pm 0.01$ \\
5 & $5.39 \pm 0.43$ & $3.40 \pm 0.10$ & $3.11 \pm 0.35$ & $3.02 \pm 0.14$ & $65.44 \pm 0.03$ \\
10 & $8.53 \pm 0.17$ & $5.55 \pm 0.21$ & $4.87 \pm 0.97$ & $3.89 \pm 0.68$ & $72.29 \pm 0.01$ \\
20 & $11.50 \pm 0.36$ & $10.45 \pm 0.34$ & $7.76 \pm 0.96$ & $7.44 \pm 0.32$ & $83.96 \pm 0.01$ \\
40 & $22.56 \pm 0.62$ & $21.11 \pm 0.87$ & $15.01 \pm 0.96$ & $11.54 \pm 0.85$ & $90.98 \pm 0.06$ \\
60 & $29.37 \pm 0.26$ & $27.43 \pm 0.13$ & $17.22 \pm 0.44$ & $13.72 \pm 0.36$ & $93.28 \pm 0.01$ \\
80 & $42.67 \pm 0.23$ & $35.04 \pm 0.19$ & $23.50 \pm 0.87$ & $19.93 \pm 0.18$ & $95.15 \pm 0.01$ \\
100 & $48.14 \pm 0.22$ & $45.57 \pm 0.25$ & $27.45 \pm 0.38$ & $23.76 \pm 0.37$ & $96.86 \pm 0.03$ \\
200 & $77.07 \pm 0.59$ & $67.71 \pm 0.76$ & $47.71 \pm 0.58$ & $40.19 \pm 0.96$ & $96.92 \pm 0.01$ \\
400 & $84.24 \pm 0.24$ & $\mathbf{7 5 . 6 1} \pm 0.48$ & $71.55 \pm 0.75$ & $67.64 \pm 0.93$ & $97.15 \pm 0.03$ \\
\hline $\mathbf{I C}_{\mathbf{5 0}}(\boldsymbol{\mu g} / \mathbf{m L})$ & $\mathbf{1 0 5 . 5 0} \pm \mathbf{1 . 0 5}$ & $\mathbf{1 1 5 . 0 0} \pm \mathbf{1 . 1 4}$ & $\mathbf{2 1 6 . 0 0} \pm \mathbf{1 . 3 4}$ & $\mathbf{2 6 9 . 5 0} \pm \mathbf{1 . 5 6}$ & $\mathbf{3 . 3 2} \pm \mathbf{0 . 0 7}$ \\
\hline
\end{tabular}


Table 2. Contents of polyphenolics compounds ( $\mathrm{mg} / 100 \mathrm{~g}$ of dry extract) in the $M$. oleifera tender and mature leaves ( $\mathrm{n}=3$ )

\begin{tabular}{lcccc}
\hline \multicolumn{1}{c}{ Name of Standard } & TLEE & MLEE & TLWE & MLWE \\
\hline Gallic acid & ND & ND & ND & ND \\
3,4-Dihydroxybenzoic acid & $201.32 \pm 1.94$ & $82.55 \pm 1.09$ & ND & ND \\
Catechin hydrate & $86.43 \pm 0.96$ & $70.79 \pm 0.91$ & $530.05 \pm 1.91$ & $207.21 \pm 0.90$ \\
Catechol & $64.09 \pm 0.95$ & $43.43 \pm 0.54$ & ND & ND \\
(-) Epicatechin & $213.08 \pm 1.96$ & $141.86 \pm 1.10$ & $84.39 \pm 0.94$ & $83.55 \pm 0.62$ \\
Caffeic acid & $\mathrm{ND}$ & $\mathrm{ND}$ & $\mathrm{ND}$ & $\mathrm{ND}$ \\
Vanillic acid & $\mathrm{ND}$ & $\mathrm{ND}$ & $\mathrm{ND}$ & $\mathrm{ND}$ \\
Syringic acid & $\mathrm{ND}$ & $\mathrm{ND}$ & $12.24 \pm 0.35$ & $3.44 \pm 0.35$ \\
Rutin hydrate & $97.25 \pm 1.74$ & $31.15 \pm 0.95$ & $35.25 \pm 0.94$ & $11.29 \pm 0.74$ \\
p-Coumaric acid & $47.35 \pm 1.54$ & $46.96 \pm 0.38$ & $\mathrm{ND}$ & $\mathrm{ND}$ \\
trans-Ferulic acid & $60.48 \pm 0.85$ & $9.17 \pm 0.11$ & $166.38 \pm 0.90$ & $62.42 \pm 0.45$ \\
Rosmarinic acid & $133.84 \pm 1.42$ & $16.23 \pm 0.76$ & $65.52 \pm 0.59$ & $60.56 \pm 0.78$ \\
Myricetin & $\mathrm{ND}$ & $\mathrm{ND}$ & $\mathrm{ND}$ & $\mathrm{ND}$ \\
Quercetin & $66.58 \pm 0.54$ & $7.67 \pm 0.46$ & $771.74 \pm 1.34$ & $483.25 \pm 1.04$ \\
trans-Cinnamic acid & $4.37 \pm 0.23$ & $0.82 \pm 0.08$ & $\mathrm{ND}$ & $\mathrm{ND}$ \\
Kaempferol & $\mathrm{ND}$ & $\mathrm{ND}$ & $\mathrm{ND}$ & $\mathrm{ND}$ \\
\hline
\end{tabular}

Values are expressed as mean \pm RSD. RSD: Relative Standard Deviation $(n=3)$. ND: Not Detected

diphenyl-2-picryl hydrazine. Antioxidants, on interaction with DPPH, either transfer an electron or hydrogen atom to $\mathrm{DPPH}$, thus neutralizing its free radical character (Naik et al., 2003). M. oleifera leaves extract significantly reduced DPPH radicals.

\subsection{Determination of polyphenolic compounds by HPLC}

The contents of the polyphenolic compounds in the leave of both $80 \%$ ethanol and water extracts of $M$. oleifera were analyzed by RP-HPLC DAD system. HPLC-DAD analysis of the polyphenolic compounds of the extracts showed Table 2. M. oleifera tender leaves of $80 \%$ ethanol extract had the more amount of 3,4dihydroxybenzoic acid, (-) epicatechin, rutin hydrate, trans-ferulic acid, rosmarinic acid and quercetin $(201.32 \pm 1.94, \quad 213.08 \pm 1.96, \quad 97.25 \pm 1.74, \quad 60.48 \pm 0.85$, $133.84 \pm 1.42$ and $66.58 \pm 0.54 \mathrm{mg} / 100 \mathrm{~g}$ dry extract respectively) than mature leaves $(82.55 \pm 1.09$, $141.86 \pm 1.10,31.15 \pm 0.95,9.17 \pm 0.11,16.23 \pm 0.76$ and $7.67 \pm 0.46 \mathrm{mg} / 100 \mathrm{~g}$ dry extract respectively). But catechin hydrate, catechol, p-coumaric acid and transcinnamic acid were closely each other in tender and mature leaves $(86.43 \pm 0.96,64.09 \pm 0.95, \quad 47.35 \pm 1.54$, $4.37 \pm 0.23$ and $70.79 \pm 0.91,43.43 \pm 0.54,46.96 \pm 0.38$, $0.82 \pm 0.08 \mathrm{mg} / 100 \mathrm{~g}$ dry extract respectively). On the other hand, Table 2 illustrates that $M$. oleifera tender leaves of water extract had the more amount of catechin hydrate, trans-ferulic acid and quercetin (530.05 \pm 1.91 , $166.38 \pm 0.90$ and $771.74 \pm 1.34 \mathrm{mg} / 100 \mathrm{~g}$ dry extract respectively) than mature leaves $(207.21 \pm 0.90$, $62.42 \pm 0.45$ and $483.25 \pm 1.04 \mathrm{mg} / 100 \mathrm{~g}$ dry extract respectively). But (-) epicatechin, syringic acid, rutin hydrate and rosmarinic acid were closely each other in tender and mature leaves $(84.39 \pm 0.94,12.24 \pm 0.35$,
$35.25 \pm 0.94, \quad 65.52 \pm 0.59$ and $83.55 \pm 0.62, \quad 3.44 \pm 0.35$, $11.29 \pm 0.74, \quad 60.56 \pm 0.78 \mathrm{mg} / 100 \mathrm{~g}$ dry extract respectively). Only syringic acid was found in water extract and 3,4-dihydroxybenzoic acid, catechol, pcoumaric acid and trans-cinnamic acid ware found in $80 \%$ ethanol extract of $M$. oleifera leaves.

Antioxidant activities not only depend on the extraction method but also on the solvent used for extraction. The presence of various antioxidant compounds like polyphenolic compounds with different chemical characteristics and polarities may or may not be soluble in a particular solvent (Turkmen et al., 2006). Polar solvents are frequently used for recovering polyphenols from plant matrices. The most available solvents are aqueous mixtures containing ethanol, methanol, acetone, and ethyl acetate. Ethanol has been known as a good solvent for polyphenol extraction and is safe for human consumption (Dai and Mumper, 2010). Similarly, water extract is also safe for human consumption. The chromatographic separations of the polyphenolic standard are shown in Figure 1. In this study, we found that $80 \%$ ethanol extract of $M$. oleifera leaves (tender and mature) contain ten polyphenolic compounds showed in Figures 2 and 3 whereas in water extract which contain seven polyphenolic compounds showed in Figures 4 and 5. This may be due to the fact that $80 \%$ of ethanol is suitable for extracting some bioactive compounds with a broad range of polarity and water are suitable for extracting some bioactive compounds with strong polarity. On the other hand, Polyphenols are mostly soluble in organic solvents that are less polar than water (Kim and Lee, 2002). The experimental results indicated that both $80 \%$ ethanol and water extract of tender leaves contained a high 


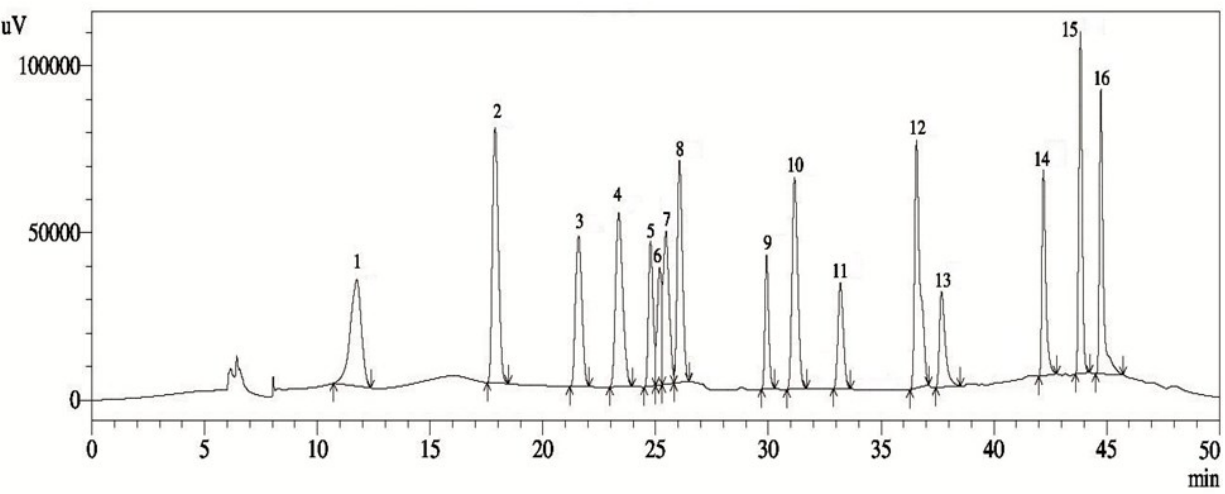

Figure 1. HPLC chromatogram of sixteen polyphenolic standards (1. Gallic acid, 2. 3,4-Dihydroxybenzoic acid, 3. Catechin hydrate, 4. Catechol, 5. (-) Epicatechin, 6. Caffeic acid, 7. Vanillic acid, 8. Syringic acid, 9. Rutin hydrate, 10. p-Coumaric acid, 11. trans-Ferulic acid, 12. Rosmarinic acid, 13. Myricetin, 14. Quercetin, 15. trans-Cinnamic acid and 16. Kaempferol)

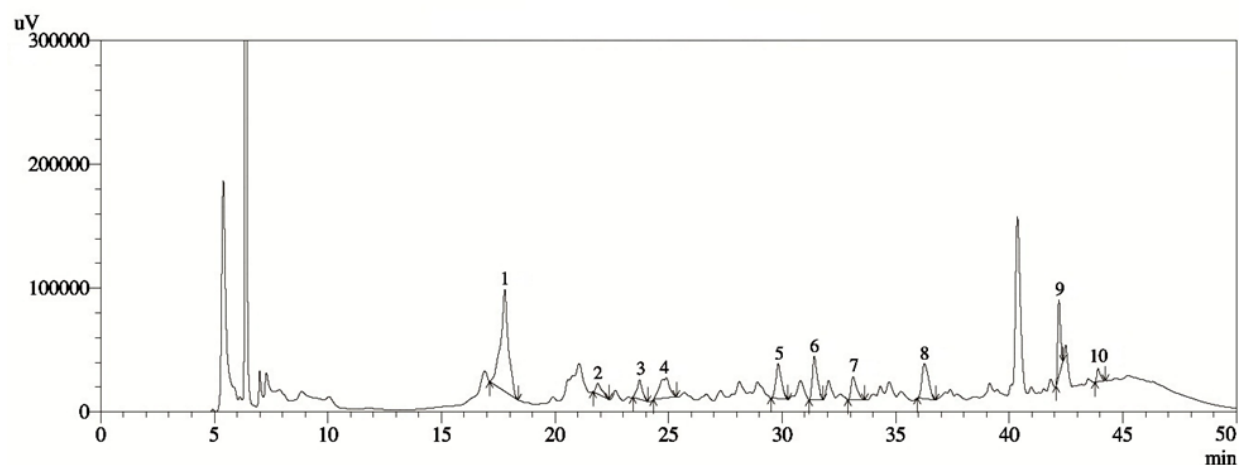

Figure 2. HPLC chromatogram of $80 \%$ ethanol extract of $M$. oleifera tender leaves: 1. 3,4-Dihydroxybenzoic acid, 2 . Catechin hydrate, 3. Catechol, 4. (-) Epicatechin, 5. Rutin hydrate, 6. p-Coumaric acid, 7. trans-Ferulic acid, 8. Rosmarinic acid, 9. Quercetin and 10. trans-Cinnamic acid

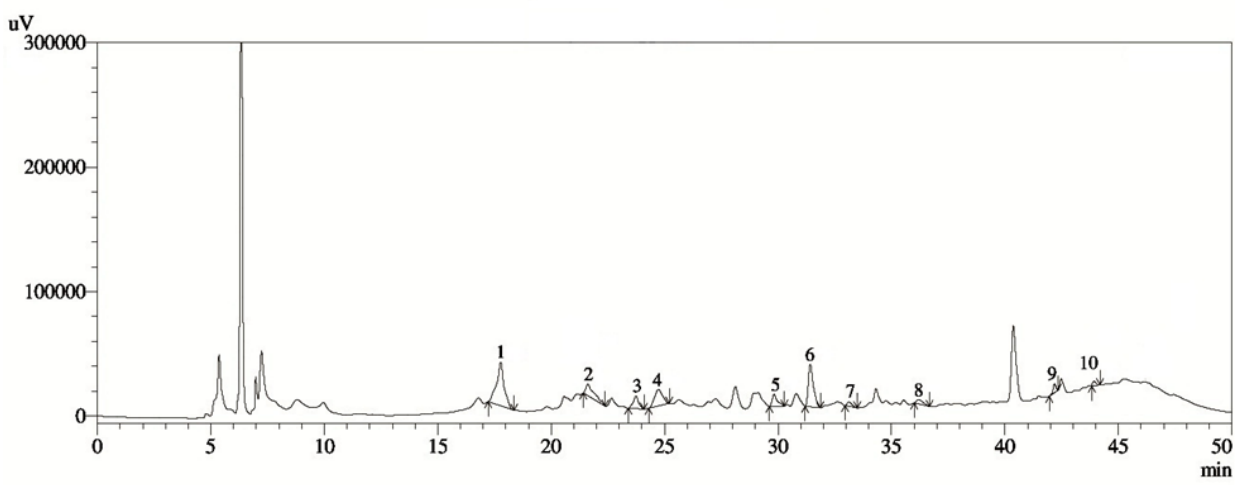

Figure 3. HPLC chromatogram of $80 \%$ ethanol extract of $M$. oleifera mature leaves: 1. 3,4-Dihydroxybenzoic acid, 2 . Catechin hydrate, 3. Catechol, 4. (-) Epicatechin, 5. Rutin hydrate, 6. p-Coumaric acid, 7. trans-Ferulic acid, 8. Rosmarinic acid, 9. Quercetin and 10. trans-Cinnamic acid

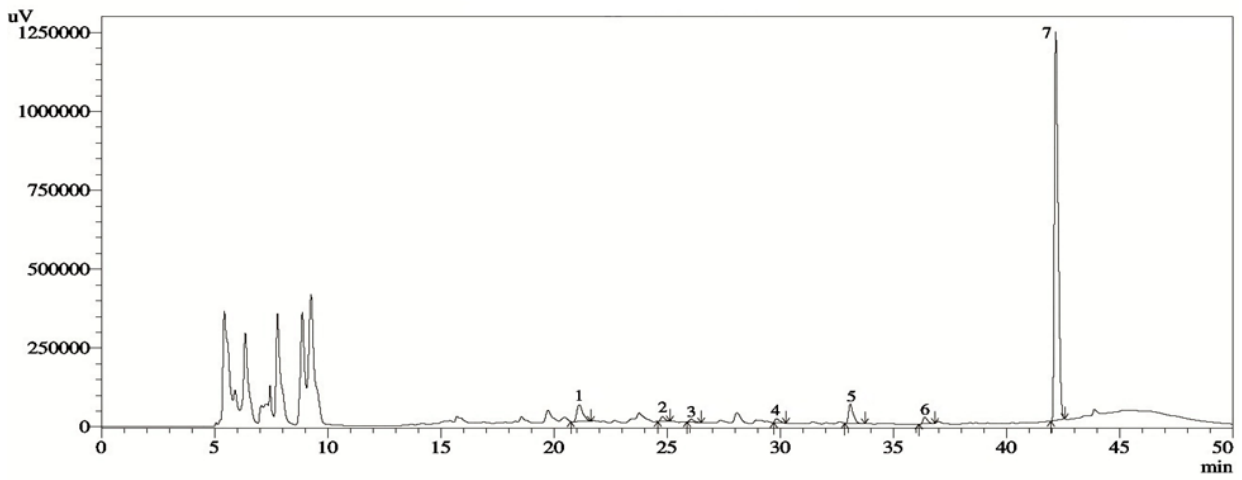

Figure 4. HPLC chromatogram of water extract of M. oleifera tender leaves: 1. Catechin hydrate, 2. (-) Epicatechin, 3. Syringic acid, 4. Rutin hydrate, 5. trans-Ferulic acid, 6. Rosmarinic acid, 7. Quercetin 


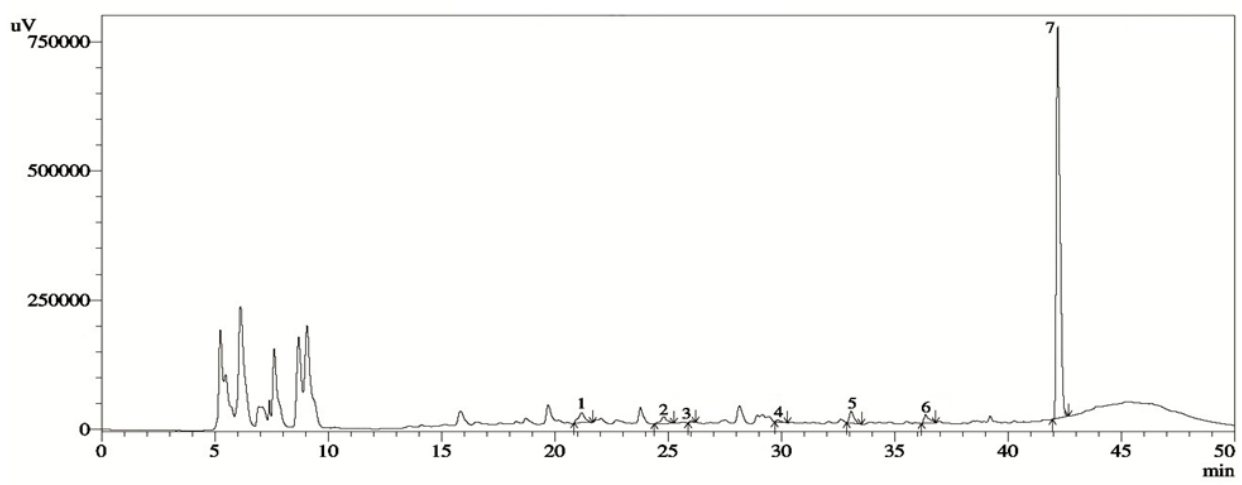

Figure 5. HPLC chromatogram of water extract of M. oleifera mature leaves: 1. Catechin hydrate, 2. (-) Epicatechin, 3. Syringic acid, 4. Rutin hydrate, 5. trans-Ferulic acid, 6. Rosmarinic acid, 7. Quercetin

concentration of polyphenolic compounds than mature leaves of $M$. oleifera. The higher levels of the compounds in the tender leaves are in accordance with the role of secondary metabolites in a plant's defence mechanism over the extensive production of reactive oxygen species (ROS). Meanwhile, as the leaves aged, the compounds are enzymatically changed to other secondary metabolites. Thus, the lower level of these marker compounds in the mature leaves (Shuib et al., 2011).

In the present study, the concentration of coumaric acid is lower value but ferulic acid is a higher value (tender leaves) than reported by Castillo-López et al. (2017) for methanol extract of M. oleifera leaves. In this study, the value of catechin, epicatechin, rutin and quercetin obtained for water extract was lower than the reported by Oboh et al. (2015) (20.19 $\pm 0.03 \mathrm{mg} / \mathrm{g}$, $29.73 \pm 0.01 \mathrm{mg} / \mathrm{g}, 60.38 \pm 0.02 \mathrm{mg} / \mathrm{g}$ and $137.81 \pm 0.01$ $\mathrm{mg} / \mathrm{g}$ respectively) for $M$. oleifera leaves. On the other hand, the results of catechin, epicatechin, rutin and quercetin observed by Ademiluyi et al. (2018) $(6.08 \pm 0.01 \mathrm{mg} / \mathrm{g}, 43.37 \pm 0.04 \mathrm{mg} / \mathrm{g}, 91.05 \pm 0.01 \mathrm{mg} / \mathrm{g}$ and $17.83 \pm 0.01 \mathrm{mg} / \mathrm{g}$ respectively) ware higher than the current experiment.

Presence of apex concentration of phenolic compounds results in this high percentage inhibition value of the extract. The scavenging ability of the phenols is due to the hydroxyl groups in their chemical construction (Hatano et al., 1989). Polyphenolic compounds can avert mutagenesis and carcinogenesis in humans when ingested up to $1 \mathrm{~g}$ from a diet rich in fruits and vegetables on a regular basis (Tanaka et al., 1988). Phytochemicals, especially polyphenols such as phenolic acids, flavonoids, phyenylpro-panoids are accountable for the free radical scavenging and antioxidant activities of plants. Therefore, these phenolic compounds account for the significant antioxidant activity of M. oleifera.

All of the polyphenolic compounds are show different types of biological activity. For example, 3,4dihydroxybenzoic acid, catechin, epicatechin, rutin, ferulic acid, rosmarinic acid and quercetin were found to be a potent antioxidant, anti-inflammatory and anticancer activity (Kakkar and Bais, 2014; Kumar and Pruthi, 2014; Wang et al., 2016; Alagawany et al., 2017; Gullón et al., 2017; Prakasha et al., 2019; Bae et al., 2020). Whereas, in our study significant amount of 3,4dihydroxybenzoic acid, catechin hydrate, (-) epicatechin, rutin hydrate, trans-ferulic acid, rosmarinic acid and quercetin are present in $M$. oleifera leaves. Therefore, $M$. oleifera leaves show significant DPPH free radical scavenging activity which may be due to the presence of different polyphenolic compounds.

\section{Conclusion}

The results of the present study showed that $80 \%$ ethanol extract of $M$. oleifera leaves showed a higher number of polyphenolic compounds than water extract. On the other hand, high amounts of polyphenolic compounds are present in tender leaves compare to mature leaves. Due to the presence of more polyphenolics compound, it also shows good antioxidant activity. From the above study showed that the concentration of polyphenolic compounds in the extracts of $M$. oleifera leaves was sufficient to be considered as a potential antioxidant supplement source. Therefore, Moringa leaves can be considered a product with potential application in the food and pharmaceutical industries, which can have positive financial and social benefits to the population.

\section{Conflict of interest}

The authors declare no conflict of interest.

\section{Acknowledgments}

We would like to thank the BCSIR authority for their approval of $\mathrm{R} \& \mathrm{D}$ project "Utilization of Moringa oleifera as a source of plant growth promoter nutrient and antioxidant chemicals" as well as providing the laboratory facilities in Chemical Research Division, BCSIR Laboratories, Dhaka, Bangladesh Council of 
Scientific and Industrial Research (BCSIR), Dhaka1205, Bangladesh.

\section{References}

Ademiluyi, A.O., Aladeselu, O.H., Oboh, G. and Boligon, A.A. (2018). Drying alters the phenolic constituents, antioxidant properties, $\alpha$-amylase, and $\alpha$-glucosidase inhibitory properties of Moringa (Moringa oleifera) leaf. Food Science and Nutrition, 6(8), 2123-2133. https://doi.org/10.1002/fsn3.770

Ahmed, K.S., Banik, R., Hossain, M.H. and Jahan, I.A. (2016). Vitamin C (L-ascorbic Acid) Content in Different Parts of Moringa oleifera Grown in Bangladesh. American Chemical Science Journal, 11 (1), 1-6. https://doi.org/10.9734/ACSJ/2016/21119

Ahmed, K.S., Jahan, I.A., Hossain, M.H., Ethane, N.J. and Saha, B. (2018). Mineral and Trace Element Content in Different Parts of Moringa oleifera Grown in Bangladesh. Current Journal of Applied Science and Technology, 31(5), 1-10. https:// doi.org/10.9734/CJAST/2018/45645

Alagawany, M., Abd El-Hack, M.E., Farag, M.R., Gopi, M., Karthik, K., Malik, Y.S. and Dhama, K. (2017). Rosmarinic acid: modes of action, medicinal values and health benefits. Animal Health Research Reviews, 18(2), 167-176. https://doi.org/10.1017/ S1466252317000081

Amaglo, N.K., Bennett, R.N., Lo Curto, R.B., Rosa E.A.S., Lo Turco V., Giuffrida, A., Lo Curto, A., Crea, F. and Timpo, G.M. (2010). Profiling selected phytochemicals and nutrients in different tissues of the multipurpose tree Moringa oleifera L., grown in Ghana. Food Chemistry, 122(4), 1047-1054. https:// doi.org/10.1016/j.foodchem.2010.03.073

Anwar, F., Latif, S., Ashraf, M. and Gilani, A.H. (2007). Moringa oleifera: A food plant with multiple medicinal uses. Phytotherapy Research, 21(1), 1725. https://doi.org/10.1002/ptr.2023

Bae, J., Kim, N., Shin, Y., Kim, S.Y. and Kim, Y. J. (2020). Activity of catechins and their applications. Biomedical Dermatology, 4, 8. https:// doi.org/10.1186/s41702-020-0057-8

Bashir, K.A., Waziri, A.F. and Musa, D.D. (2016). Moringa oleifera, a potential miracle tree; a review. IOSR Journal of Pharmacy and Biological Sciences, 11(6), 25-30.

Castillo-López, R.I., León-Félix, J., Angulo-Escalante, M.A., Gutiérrez-Dorado, R., Muy-Rangel, M.D. and Heredia, J.B. (2017). Nutritional and phenolic characterization of Moringa oleifera leaves grown in Sinaloa, México. Pakistan Journal of Botany, 49(1), 161-168.

Cheynier, V. (2005). Polyphenols in foods are more complex than often thought. The American Journal of Clinical Nutrition, 81(1), 223S-229S. https:// doi.org/10.1093/ajcn/81.1.223S

Cuellar-Nuñez, M.L., Luzardo-Ocampo, I., CamposVega, R., Gallegos-Corona, M.A., González de Mejía, E. and Loarca-Piña, G. (2018). Physicochemical and nutraceutical properties of moringa (Moringa oleifera) leaves and their effects in an in vivo AOM/DSSinduced colorectal carcinogenesis model. Food Research International, 105, 159-168. https://doi.org/10.1016/ j.foodres.2017.11.004

Dai, J. and Mumper, R.J. (2010). Plant phenolics: extraction, analysis and their antioxidant and anticancer properties. Molecules, 15(10), 7313-7352. https://doi.org/10.3390/molecules 15107313

Fahey, J.W. (2005). Moringa oleifera: a review of the medical evidence for its nutritional, therapeutic, and prophylactic properties. Part 1. Trees for Life Journal, 1, 5.

Falowo, A.B., Mukumbo, F.E., Idamokoro, E.M., Lorenzo, J.M., Afolayan, A.J. and Muchenje, V. (2018). Multi-functional application of Moringa oleifera Lam. in nutrition and animal food products: a review. Food Research International, 106, 317334. https://doi.org/10.1016/j.foodres.2017.12.079

Govindarajan, R., Rastogi, S., Vijayakumar, M., Shirwaikar, A., Rawat, A.K.S., Mehrotra, S. and Pushpangadan, P. (2003). Studies on the Antioxidant Activities of Desmodium gangeticum. Biological and Pharmaceutical Bulletin, 26(10), 1424-1427. https:// doi.org/10.1248/bpb.26.1424

Gullón, B., Lú-Chau, T.A., Moreira, M.T., Lema, J.M. and Eibes, G. (2017). Rutin: A review on extraction, identification and purification methods, biological activities and approaches to enhance its bioavailability. Trends in Food Science and Technology, 67, 220-235. https://doi.org/10.1016/ j.tifs.2017.07.008

Hatano, T., Edamatsu, R., Hiramatsu, M., Mori, A., Fujita, Y., Yasuhara, T., Yoshida, T. and Okuda, T. (1989). Effects of the interaction of tannins with coexisting substances. VI: effects of tannins and related polyphenols on superoxide anion radical and on 1, 1diphenyl-2-picrylhydrazyl radical. Chemical and Pharmaceutical Bulletin, 37(8), 2016-2021. https:// doi.org/10.1248/cpb.37.2016

Ibrahim, N.M., Mat, I., Lim, V. and Ahmad, R. (2013), Antioxidant activity and phenolic content of Streblus asper leaves from various drying methods. Antioxidants, 2(3), 156-166. https://doi.org/10.3390/ antiox 2030156

Jahan, I.A., Hossain, M.H., Ahmed, K.S., Sultana, J., Biswas, P.K. and Nada, K. (2018). Antioxidant activity of Moringa oleifera seed extracts. Oriental 
Pharmacy and Experimental Medicine, 18(4), 299307. https://doi.org/10.1007/s13596-018-0333-y

Kakkar, S. and Bais, S. (2014). A Review on Protocatechuic Acid and Its Pharmacological Potential. ISRN Pharmacology, 2014, 952943. https://doi.org/10.1155/2014/952943

Kim, D.O. and Lee, C.Y. (2002). Extraction and isolation of polyphenolics. Current Protocols in Food Analytical Chemistry, 6(1), I1.2.1-I1.2.12. https://doi.org/10.1002/0471142913.fai0102s06

Kumar, N. and Pruthi, V. (2014). Potential applications of ferulic acid from natural sources. Biotechnology Reports, 4, 86-93. https://doi.org/10.1016/ j.btre.2014.09.002

Kumar, P.S., Mishra, D., Ghosh, G. and Panda, C.S. (2010). Medicinal uses and pharmacological properties of Moringa oleifera. International Journal of Phytomedicine, 2(3), 210-216.

Luqman, S., Srivastava, S., Kumar, R., Maurya, A.K. and Chanda, D. (2012). Experimental assessment of Moringa oleifera leaf and fruit for its antistress, antioxidant, and scavenging potential using in vitro and in vivo assays. Evidence-Based Complementary and Alternative Medicine, 2012, 519084. https:// doi.org/10.1155/2012/519084

Manach, C., Scalbert, A., Morand, C., Rémésy, C. and Jiménez, L. (2004). Polyphenols: food sources and bioavailability. The American Journal of Clinical Nutrition, 79(5), 727-747. https://doi.org/10.1093/ ajcn/79.5.727

Manach, C., Williamson, G., Morand, C., Scalbert, A. and Rémésy, C. (2005). Bioavailability and bioefficacy of polyphenols in humans. I. Review of 97 bioavailability studies. American Journal of Clinical Nutrition, 81(1), 230S-242S. https:// doi.org/10.1093/ajcn/81.1.230S

Naik, G.H., Priyadarsini, K.I., Satav, J.G., Banavalikar, M.M., Sohoni, D.P., Biyani, M.K. and Mohan, H. (2003). Comparative antioxidant activity of individual herbal components used in Ayurvedic medicine. Phytochemistry, 63(1), 97-104. https:// doi.org/10.1016/S0031-9422(02)00754-9

Nimse, S.B. and Pal, D. (2015). Free radicals, natural antioxidants, and their reaction mechanisms. RSC Advances, 5, 27986-28006. https://doi.org/10.1039/ C4RA13315C

Oboh, G., Ademiluyi, A.O., Ademosun, A.O., Olasehinde, T.A., Oyeleye, S.I., Boligon, A.A. and Athayde, M.L. (2015). Phenolic Extract from Moringa oleifera Leaves inhibits key enzymes linked to erectile dysfunction and oxidative stress in rats' penile tissues. Biochemistry Research International, 2015, $175950 . \quad$ https:// doi.org/10.1155/2015/175950
Prakasha, M., Basavarajb, B.V. and Murthyc, K.N.C. (2019). Biological functions of epicatechin: Plant cell to human cell health. Journal of Functional Foods, 52, 14-24. https://doi.org/10.1016/ j.jff.2018.10.021

Proestos, C., Bakogiannis, A., Psarianos, C., Koutinas, A.A., Kanellaki, M. and Komaitis, M. (2005). High performance liquid chromatography analysis of phenolic substances in Greek wines. Food Control, 16(4), 319-323. https://doi.org/10.1016/ j.foodcont.2004.03.011

Shuib, N.H., Shaari, K., Khatib, A., Maulidiani, Kneer, R., Zareen, S., Raof, S.M., Lajis, N.H. and Neto, V. (2011), Discrimination of young and mature leaves of Melicope ptelefolia using $1 \mathrm{H}$ NMR and multivariate data analysis. Food Chemistry, 126(2), 640-645.

https://doi.org/10.1016/ j.foodchem.2010.10.043

Sreelatha, S. and Padma, P.R. (2009). Antioxidant activity and total phenolic content of Moringa oleifera leaves in two stages of maturity. Plant Foods for Human Nutrition, 64(4), 303-311. https:// doi.org/10.1007/s11130-009-0141-0

Stohs, S.J. and Hartman, M.J. (2015). Review of the safety and efficacy of Moringa oleifera. Phytotherapy Research, 29(6), 796-804. https:// doi.org/10.1002/ptr.5325

Tanaka, M., Kuie, C.W., Nagashima, Y. and Taguchi, T. (1988). Application of antioxidative Maillard reaction products from histidine and glucose to sardine products. Bulletin of the Japanese Society of Scientific Fisheries, 54(8), 1409-1414. https:// doi.org/10.2331/suisan.54.1409

Turkmen, N., Sari, F. and Velioglu, Y.S. (2006). Effects of extraction solvents on concentration and antioxidant activity of black and black mate tea polyphenols determined by ferrous tartrate and Foline-Ciocalteu methods. Food Chemistry, 99(4), 835-841.

https://doi.org/10.1016/ j.foodchem.2005.08.034

Wang, W., Sun, C., Mao, L., Ma, P., Liu, F., Yang, J. and Gao, Y. (2016). The biological activities, chemical stability, metabolism and delivery systems of quercetin: A review. Trends in Food Science and Technology, 56, 21-38. https://doi.org/10.1016/ j.tifs.2016.07.004

Win, M.M., Abdul-Hamid, A., Baharin, B.S., Anwar, F., Sabu, M.C. and Pak-Dek, M.S. (2011). Phenolic compounds and antioxidant activity of peanut's skin, hull, raw kernel and roasted kernel flour. Pakistan Journal of Botany, 43(3), 1635-1642. 